\title{
Tuberculous Lymphadenitis at Penang General Hospital, Malaysia
}

\author{
Amer Hayat Khan ${ }^{c}$ Syed Azhar Syed Sulaiman ${ }^{c}$ Abdul Razak Muttalifa \\ Mohamed Azmi Hassali ${ }^{b}$ Tahir Mehmood Khan ${ }^{c, d}$ \\ aDepartment of Respiratory Medicine, Penang General Hospital, ${ }^{b}$ Discipline of Social and Administrative Pharmacy, \\ School of Pharmaceutical Sciences, Universiti Sains Malaysia, and 'School of Pharmaceutical Sciences, \\ Universiti Sains Malaysia, Penang, Malaysia; ${ }^{\mathrm{d} C o l l e g e ~ o f ~ C l i n i c a l ~ P h a r m a c y, ~ K i n g ~ F a i s a l ~ U n i v e r s i t y, ~ A l-A h s a, ~ S a u d i ~ A r a b i a ~}$
}

\section{Key Words}

Tuberculous lymphadenitis • Fine-needle aspiration

\begin{abstract}
Objective: To evaluate the incidence, treatment and clinical outcomes of tuberculous (TB) lymphadenitis at Penang General Hospital, Malaysia. Materials and Methods: Penang General Hospital is the referral center for all tuberculosis patients in the state of Penang. Patient records were reviewed to identify patients with confirmed diagnosis of TB lymphadenitis between January 2006 and December 2008. Data were analyzed using SPSS version 15. Results: Of 1,548 tuberculosis cases, 109 (7.0\%) patients had TB lymphadenitis. The mean age was $36.4 \pm 12.87$ years and of the 109 patients with TB lymphadenitis, 35 (33.0\%), 37 (34.0\%) and 36 (33.0\%) were observed for 2006, 2007 and 2008, respectively. Ethnically, 45 (41.3\%) were Malay followed by 37 Chinese (33.9\%). Among risk factors for TB lymphadenitis, HIV and diabetes mellitus were seen in 17 (15.6\%) and 11 (10.0\%) patients, respectively. Cough and fever were the most frequently reported symptoms. In a majority of cases $(n=90,82.5 \%)$ positive results were obtained for fine-needle aspiration (FNA). Directly observed therapy was given to all patients. Sixtytwo (56.9\%) patients were successfully treated, and 5 (4.6\%)
\end{abstract}

patients died during the treatment. Conclusion: There was no increase in the incidence of TB lymphadenitis over the 3-year study period. The incidence was slightly higher in male than female gender and in Malay (ethnic group). Diabetes mellitus and HIV were the most commonly reported risk factors. FNA is the most reliable diagnostic test.

Copyright $\odot 2010$ S. Karger AG, Basel

\section{Introduction}

Tuberculosis, a deadly bacterial infection, can spread to other body tissues and organs through the blood stream and the lymphatic system [1]. With the global increase in the incidence of human immunodeficiency virus (HIV) there has been a steady increase in extrapulmonary tuberculosis as exemplified in the United States [2] and Malaysia [3], where 21\% of extrapulmonary tuberculosis cases were associated with HIV infection [3]. Tuberculous (TB) lymphadenitis also known as scrofula (King's Evil) [4] was first described 3,000 years ago and is one of the common forms of extrapulmonary tuberculosis. In areas where tuberculosis is endemic, TB adenitis is a common cause of lymphadenopathy [5]. The cervix is the most common site of TB adenitis, while other sites

\section{KARGER}

Fax +4161306 1234

E-Mail karger@karger.ch

www.karger.com
(C) 2010 S. Karger AG, Basel

$1011-7571 / 11 / 0201-0080 \$ 38.00 / 0$

Accessible online at:

www.karger.com/mpp
Amer Hayat Khan

School of Pharmaceutical Sciences

Universiti Sains Malaysia

Penang 11800 (Malaysia)

Tel. +60 4658 5501, Fax +60 4657 0017, E-Mail amerhayat@ymail.com 
include intrathoracic, intra-abdominal, and occasionally, axillary, inguinal and intramammary [6, 7]. TB lymphadenitis comprises $30-50 \%$ of extrapulmonary tuberculosis cases in the US [5], and 33.5\% in Malaysia [8]. A wide excision and prolonged antituberculosis therapy were the only available treatment options in the 20th century [9], but now a short course of rifampicin has been used successfully [10].

Malaysia, a multicultural and multiethnic country, has a population slightly more than 26 million [11] and an area of $33,000 \mathrm{~km}^{2}$. In Malaysia, tuberculosis is among the top five communicable diseases with an incidence rate of 62.56 per 100,000 and a mortality rate of 5.37 per 100,000 [11]. The state of Penang is the 8th most populous state in Malaysia and among the top five states with the highest tuberculosis burden [12]. Pulmonary tuberculosis has been the center of attraction for the researchers for a number of years [13]. However, only a handful of studies [14] have been reported on extrapulmonary tuberculosis, especially, TB lymphadenitis. The current study was designed to expand our current knowledge and to gather baseline data on the incidence, diagnosis, complications, management and treatment outcomes of tuberculous lymphadenitis in a teaching hospital.

\section{Subjects and Methods}

The study protocol was approved by the Clinical Research Center, Penang General Hospital and Ministry of Health, Malaysia. Informed consent was taken from the subjects before performing needle biopsy test.

\section{Study Location}

Penang is one of the 13 states and is geographically situated in northern Malaysia. Penang is a multicultural state comprising Malay (42.5\%), Chinese (46.5\%), Indian (10.6\%) and other minorities (0.4\%), with an estimated population of 1.5 million [12].

\section{Subjects}

A total of 1,548 cases were registered for tuberculosis treatment from 1st January 2006 to December 2008 at the Respiratory Clinic of Penang GH. This center is a tertiary level reference center for respiratory diseases in the state of Penang, Malaysia. Any person with a respiratory problem in the state of Penang can attend this center without a physician referral.

All patients with a confirmed diagnosis of TB lymphadenitis were included in the study. For those who had completed treatment (January 2006 to May 2007), data were obtained from medical records while, for those undergoing treatment (June 2007 to December 2008) data were collected during the course of the treatment. From each medical case file, the patient history, physical findings, chest radiographs and laboratory investigation were reviewed in order to obtain maximum information about the type and severity of TB. In addition, demographic factors, lifestyle (smoking habit and alcohol use) and clinical characteristics were recorded. Among clinical characteristics comorbid medical complications like diabetes mellitus and HIV, medications for therapy and therapeutic outcomes were recorded.

\section{Categories of Patients for Registration on Diagnosis}

New patient: a patient who has never had treatment for tuberculosis or has taken antituberculosis drugs for less than 1 month; relapse: a patient who was previously treated for tuberculosis and was declared cured or treatment completed, and later diagnosed with bacteriologically positive (smear or culture) tuberculosis; failure: a patient who, while on treatment, had positive sputum smear at 5 months or later during the course of treatment; return after default: a patient who returned to treatment with positive bacteriology, following interruption of treatment for 2 months or more; transfer in: a patient who was transferred from another tuberculosis registry to continue treatment.

\section{Diagnosis}

Diagnosis of tuberculosis and extrapulmonary tuberculosis were based on the World Health Organization definitions $[15,16]$. For tuberculosis the patient was bacteriologically confirmed, or was diagnosed by a clinician. Extrapulmonary tuberculosis such as pleura, lymph nodes, abdomen, genitourinary tract, skin, joints and bones, meninges, diagnosis was based on one culture-positive specimen, histological or strong clinical evidence consistent with active extrapulmonary tuberculosis, followed by a decision by a clinician to treat with a full course of antituberculosis chemotherapy.

The diagnosis of TB lymphadenitis was based on fine-needle aspiration (FNA) biopsy. The diagnosis was also supported by tuberculin skin test, sputum culture for acid-fast bacilli. However, to further ensure the diagnosis of HIV-positive patients and those with the comorbid diabetes mellitus records from the medical, infectious and venereal diseases clinics were traced and reviewed.

\section{Treatment Outcome}

A patient who was sputum smear-negative in the last month of treatment and on at least one previous occasion was assumed to be cured. A patient who was sputum smear-positive at 5 months or later during treatment was categorized as treatment failure. A patient who had completed treatment but who did not meet the criteria to be classified as cured or failure was categorized as treatment completed. A patient who died for any reason during the course of treatment was categorized as dead. A patient whose treatment was interrupted for 2 consecutive months or more was categorized as defaulter. A patient who was transferred to another recording and reporting unit and for whom the treatment outcome was not known was categorized as transferred out. As a whole the sum of patients cured and those who completed treatment was categorized as treatment success.

\section{Data Analysis}

The data were analyzed using the statistical software SPSS version 15 . The data with quantitative variables are expressed as mean $( \pm \mathrm{SD})$ and range while the qualitative variables were estimated by frequency and percentage. Furthermore, non-parametric statistics (i.e. $\chi^{2}$ and Fisher's exact test) were used to find out the association among the variables. $p$ values less than 0.05 were considered significant. 


\section{Results}

\section{Patient Demographics}

The demographics of the patients are given in table 1 . Of the 1,548 patients, 109 (7.04\%) had TB lymphadenitis, of whom 58 (53.2\%) were males and 51 (46.8\%) females. The mean age of patients with TB lymphadenitis was 36.4 \pm 12.87 years (7-72). Incidence of TB lymphadenitis was highest among the age group of 21-30 years (29.4\%) and the difference was statistically significant $(\mathrm{p}=0.007)$. Moreover a high prevalence of TB lymphadenitis was observed among Malays (41.3\%) followed by Chinese (33.9\%), then Indians and others.

The most common comorbid condition reported in the present study was HIV $(\mathrm{n}=17,15.6 \%)$. Of these 14 (82.35\%) were males. The incidence of TB lymphadenitis within the HIV-infected group of patients was found to be statistically significant among male patients $(\mathrm{p}=$ 0.006).

\section{Clinical Symptoms}

A majority of patients $(\mathrm{n}=83,76.15 \%)$ reported cough, $80(73.39 \%)$ fever (53.21\%) and night sweats (58\%). However, loss of weight and loss of appetite were more significantly reported by female than male patients. Details of the reported symptoms are listed in table 2 .

\section{Diagnosis}

Of the 109 patients, 90 (90.8\%) were diagnosed by using FNA, followed by chest radiography $(\mathrm{n}=87,79.8 \%)$ and erythrocyte sedimentation rate $(\mathrm{n}=86,78.9 \%)$ as given in table 3. The majority were diagnosed as hilar/ paratracheal $(\mathrm{n}=93,85.32 \%)$, followed by lymphatic cervical $(\mathrm{n}=12,11 \%)$, lymphatic axillary $(\mathrm{n}=3,2.75 \%)$, and lymphadenopathy in the neck $(n=1,0.9 \%)$.

\section{Management and Outcomes}

All patients received directly observed therapy for a minimum of 9 months (range 9-14 months). 2EHRZ+ $6 \mathrm{H} 2 \mathrm{R} 2$ was the therapeutic combination used for the majority $(\mathrm{n}=22,20.2 \%)$ of the patients. Details about the therapeutic combinations used are given in table 4 . Based on the clinical outcome the duration of intensive phase was increased to 3 months in 29 (26.6\%) patients. Sixtytwo (56.9\%) of the patients were successfully treated. In 9 (8.2\%) patients treatment failed and $5(4.6 \%)$ patients expired during the course of therapy.
Table 1. Demographic information of the 109 patients with TB lymphadenitis

\begin{tabular}{|c|c|c|c|}
\hline \multicolumn{3}{|c|}{ Demographic variables } & \multirow{2}{*}{$\begin{array}{l}\text { p value } \\
0.197^{c}\end{array}$} \\
\hline Mean age $\mathrm{a}^{\mathrm{a}}$ & $\begin{array}{l}\text { all } \\
\text { male } \\
\text { female }\end{array}$ & $\begin{array}{l}36.4 \pm 12.87(7-72) \\
39 \pm 11.7(17-72) \\
32 \pm 13.3(7-63)\end{array}$ & \\
\hline Gender & $\begin{array}{l}\text { male } \\
\text { female }\end{array}$ & $\begin{array}{l}58(53.2) \\
51(46.8)\end{array}$ & $0.197^{\mathrm{c}}$ \\
\hline Year & $\begin{array}{l}2006 \\
2007 \\
2008\end{array}$ & $\begin{array}{l}36(33.0) \\
37(34.0) \\
36(33.0)\end{array}$ & $0.058^{*, \mathrm{~b}}$ \\
\hline Location & $\begin{array}{l}\text { hospital } \\
\text { prison }\end{array}$ & $\begin{array}{c}100(91.7) \\
9(8.3)\end{array}$ & $0.09^{c}$ \\
\hline Ethnicity & $\begin{array}{l}\text { Malay } \\
\text { Chinese } \\
\text { Indian } \\
\text { Indonesian } \\
\text { other }\end{array}$ & $\begin{array}{c}45(41.3) \\
37(33.9) \\
18(16.5) \\
3(2.8) \\
7(6.4)\end{array}$ & $0.016^{*, c}$ \\
\hline Age, years & $\begin{array}{l}<20 \\
21-30 \\
31-40 \\
41-50 \\
51-60 \\
\text { over } 60\end{array}$ & $\begin{array}{c}8(7.3) \\
32(29.4) \\
20(18.3) \\
18(16.5) \\
21(19.3) \\
10(9.2)\end{array}$ & $0.007^{*, \mathrm{c}}$ \\
\hline $\begin{array}{l}\text { Marital } \\
\text { status }\end{array}$ & $\begin{array}{l}\mathrm{NM} \\
\text { single } \\
\text { married } \\
\text { divorced }\end{array}$ & $\begin{array}{c}45(41.3) \\
15(13.8) \\
47(43.1) \\
2(1.8)\end{array}$ & $0.209^{c}$ \\
\hline $\begin{array}{l}\text { Employment } \\
\text { status }\end{array}$ & $\begin{array}{l}\text { NM } \\
\text { employed } \\
\text { unemployed } \\
\text { business } \\
\text { retired }\end{array}$ & $\begin{array}{c}29(26.6) \\
34(31.2) \\
33(30.3) \\
1(0.9) \\
3(2.8)\end{array}$ & $0.608^{c}$ \\
\hline Smoker & $\begin{array}{l}\text { yes } \\
\text { ex-smoker }\end{array}$ & $\begin{array}{c}36(33.0) \\
6(5.5)\end{array}$ & $0.000^{*, \mathrm{c}}$ \\
\hline Alcohol & $\begin{array}{l}\text { yes } \\
\text { ex-drinker }\end{array}$ & $\begin{array}{r}10(9.2) \\
5(4.6)\end{array}$ & $0.014^{*, c}$ \\
\hline $\begin{array}{l}\text { Case } \\
\text { category }\end{array}$ & $\begin{array}{l}\text { new cases } \\
\text { defaulters } \\
\text { relapse }\end{array}$ & $\begin{array}{c}97(89.0) \\
5(4.6) \\
7(6.4)\end{array}$ & $0.471^{\mathrm{c}}$ \\
\hline $\begin{array}{l}\text { Tuberculosis } \\
\text { with }\end{array}$ & $\begin{array}{l}\text { diabetes mellitus } \\
\text { HIV/AIDS }\end{array}$ & $\begin{array}{l}11(10.1) \\
17(15.6)\end{array}$ & $\begin{array}{l}0.465^{\mathrm{b}} \\
0.006^{*, \mathrm{~b}}\end{array}$ \\
\hline
\end{tabular}

Data shown as number of patients with percentage in parentheses. NM = Not mentioned in record. An asterisk indicates statistical significance.

${ }^{\mathrm{a}}$ Mean $\pm \mathrm{SD}$ and range. ${ }^{\mathrm{b}} \chi^{2}$ test. ${ }^{\mathrm{c}}$ Fisher's exact test. 
Table 2. Symptoms reported by 109 patients with TB lymphadenitis

\begin{tabular}{lcccl}
\hline Symptoms & Male $(\mathrm{n}=58)$ & Female $(\mathrm{n}=51)$ & Total $(\mathrm{n}=109)$ & p value \\
\hline Night sweat & $31(53.4)$ & $27(52.9)$ & $58(53.2)$ & 0.958 \\
Cough & $45(77.6)$ & $38(74.5)$ & $83(76.1)$ & 0.707 \\
Sputum & $27(46.6)$ & $21(41.2)$ & $48(44.0)$ & 0.827 \\
Shortening of breath & $19(32.8)$ & $15(29.4)$ & $34(31.2)$ & 0.707 \\
Fever & $43(74.1)$ & $37(72.5)$ & $80(73.4)$ & 0.851 \\
Swelling of lymph nodes & $8(13.8)$ & $17(33.3)$ & $25(23.0)$ & $0.015^{*}$ \\
Fatigue & $2(3.4)$ & $2(3.9)$ & $4(3.7)$ & 0.097 \\
Loss of appetite & $32(55.2)$ & $40(78.4)$ & $72(66.1)$ & $0.002^{*}$ \\
Loss of weight & $29(50.0)$ & $40(78.4)$ & $69(63.3)$ & $0.011^{*}$ \\
Hemoptysis & $6(10.3)$ & $14(27.5)$ & $20(18.3)$ & $0.021^{*}$ \\
Chills & $5(8.6)$ & $7(13.7)$ & $12(11.0)$ & 0.396 \\
Chest pain & $7(12.1)$ & $10(19.6)$ & $17(15.6)$ & 0.279 \\
Backache & 0 & $2(3.9)$ & $2(1.8)$ & 0.128 \\
Clubbing & $7(12.1)$ & $12(23.5)$ & $19(17.4)$ & 0.116 \\
Lethargy & $3(5.2)$ & $2(3.9)$ & $5(4.6)$ & 0.755 \\
Abdominal swelling & $1(1.7)$ & 0 & $1(0.9)$ & 0.346 \\
\hline
\end{tabular}

Data shown as number of patients with percentage in parentheses. ${ }^{*}$ Significant by $\chi^{2}$ test.

Table 4. Therapeutic combination used

\begin{tabular}{lc}
\hline Drug regimen & Patients, $\mathrm{n}(\%)$ \\
\hline 2EHRZ+6H2R2 & $22(20.2)$ \\
2EHRZ & $19(17.4)$ \\
3EHRZ & $15(13.7)$ \\
3EHRZ+5HR & $14(12.8)$ \\
3EHRZ+4H2R2 & $13(11.9)$ \\
2EHRZ+6HR & $9(8.3)$ \\
2SEHRZ+6H2R2 & $6(5.5)$ \\
3EHR+4H2R2 & $5(4.6)$ \\
3SEHR+6HR & $2(1.8)$ \\
3 SEHR+9H2R2 & $2(1.8)$ \\
3HRZ+9HR & $1(0.91)$ \\
4EHR+5EHR & $1(0.91)$ \\
\hline
\end{tabular}

$\mathrm{E}=$ Ethambutol; $\mathrm{H}$ = isoniazid; $\mathrm{R}$ = rifampicin; $\mathrm{Z}$ = pyrazinamide; $\mathrm{S}=$ streptomycin.

Table 3. Diagnostic procedure used

\begin{tabular}{ll}
\hline Procedure & Patients, $\mathrm{n}(\%)$ \\
\hline FNA & $90(90.8)$ \\
Chest radiograph & $87(79.8)$ \\
Erythrocyte sedimentation rate & $86(78.9)$ \\
Tuberculin skin test & $79(72.5)$ \\
Sputum culture & $77(70.6)$ \\
Acid-fast bacilli smear & $51(46.8)$ \\
\hline
\end{tabular}

TB Lymphadenitis

\section{Discussion}

TB lymphadenitis is the most common form of extrapulmonary tuberculosis especially among young adult males [7]. Tuberculosis is responsible for $30-52 \%$ of diseases causing lymphadenopathy in developing countries, whereas in developed countries it is only 1.6\% [17].

In terms of age, the incidence of TB lymphadenitis was significantly higher in the age group 21-30 years followed by $51-60,31-40$, and $41-50$ years, confirming a previous report [18]. The reasons for this high incidence in the age group 21-30 years may be weakening of the immune system due to smoking, which may indirectly increase the susceptibility to opportunistic infections $[19,20]$ and the environmental pollution $[18,21]$. The findings of the current study contradict the findings reported by Koffi et al. [19] and Gajalakshmi [20], because a majority (19.3\%) of the patients in this age group were nonsmokers.

Concerning ethnicity, a high incidence of TB lymphadenitis was observed among Malays (41.3\%); these findings contradict those of the previous study that had reported a higher incidence among Chinese [22]. Overall, a high risk of TB lymphadenitis was observed among the patients with HIV/AIDS (15.6\%), thereby confirming the findings of Polesky et al. [23] and Shafer et al. [3], who had reported HIV/AIDS to be the most common underlying condition. 
The majority of patients in our study presented with typical symptoms and signs, which were similar to the findings reported in other studies [24, 25]. However, there are other reports that suggest atypical symptoms and signs to be more common among TB lymphadenitis patients [23].

In agreement with the findings of other studies [23, 26], FNA of the lymph nodes was the most consistent method to identify the bacteriologic agent responsible for lymphadenopathy. In addition, tuberculin skin test was a basic tool in the diagnosis of tuberculosis infection among $72.5 \%$ of patients [27]. On the other hand, sputum culture was found to be the least reliable test for the diagnosis of TB lymphadenitis.

\section{Conclusions}

There was no increase in the incidence of TB lymphadenitis over the 3-year study period reported at Penang General Hospital. The incidence of TB lymphadenitis was slightly higher in males than in females and higher in Malays than in other ethnic groups. 2EHRZ (ethambutol, isonaiazid, rifampicin, pyrazinamide) $+6 \mathrm{H} 2 \mathrm{R} 2$ (ethambutol, rifampicin) combination therapy showed a better treatment outcome than others. Diabetes mellitus and HIV were the risk factors. FNA was the most reliable diagnostic test.

\section{Acknowledgment}

The authors would like to thank the Institute of Postgraduate Studies, Universiti Sains Malaysia for providing a USM fellowship to carry out the project successfully.

\section{References}

1 Fuentes ZM, Caminero JA: Controversies in the treatment of extra pulmonary tuberculosis. Arch Bronconeumol 2006;42:194-201.

2 Angeline AL, Bennett T: Tuberculous lymphadenitis. Dis Mon 2006;53:10-15.

-3 Shafer RW, Kim DS, Weiss JP, Quale JM: Extrapulmonary tuberculosis in patients with human immunodeficiency virus infection. Medicine 1991;70:384-397.

4 Grzybowski S, Allen EA: History and importance of scrofula. Lancet 1995;346:1472-1474.

5 Angeline AL, Bennett T: Tuberculous lymphadenitis. Dis Mon 2007;53:10-15.

-6 Artenstein AW, Kim JH, Williams WJ, Raymond CY: Isolated peripheral tuberculous lymphadenitis in adults: current clinical and diagnostic issues. Clin Infect Dis 1995;20: 876-882.

7 Narang P, Narang R, Mendiratta DK, Sharma SM, Tyagi NK: Prevalence of tuberculous lymphadenitis in children in Wardha district, Maharashtra State, India. Int J Tuberc Lung Dis 2005;9:188-194.

$\checkmark 8$ Nissapatorn V, Kuppusamy I, Sim BL, Quek KF, Khairul AA: Tuberculosis in HIV/AIDS patients: a Malaysian experience. Southeast Asian J Trop Med Public Health 2005;36: 946-953.

-9 Castro DJ, Hoover L, Zuckerbraun L: Cervical mycobacterial lymphadenitis: medical vs surgical management. Arch Otolaryngol 1985;111:816-819.

10 Campbell IA: The treatment of superficial tuberculosis lymphadenitis. Tubercle 1990; 71:1-3.
11 Health Facts 2006. Ministry of Health Malaysia, 2007. www.moh.gov.my/ststic/ health_facts_2006.pdf (accessed November 15, 2008).

12 Penang Statistics. Quarter 2, 2007 by SocioEconomic and Environmental Research Institute. http://www2.seri.com.my/Penang\% 20Statistics/2007/Q2-April-June-2007-1.pdf (accessed November 15, 2008).

13 Takahashi M: Pulmonary tuberculosis. Treatment. RFLP analysis of Mycobacterium tuberculosis (in Japanese). Curr Ther 2000; 18:1512-1516.

14 Henning G, Christian T, Clemens K, Helgo M, Detlef KK: Assessment of lymph node tuberculosis in Northern Germany: a clinical review. Chest 2002;121:1177-1182.

15 Practice Guidelines for the Control and Management of Tuberculosis, ed 2. Ministry of Health Malaysia and Academy of Medicine Malaysia 2002. www.moh.gov.my/mohportal/downloadservlet?id $=580 \&$ type $=2$ (accessed November 10, 2008).

16 WHO: Revised International Definitions in Tuberculosis Control. Int J Tuberc Lung Dis 2001;5:213-215.

17 Sloane MF: Mycobacterial lymphadenitis in tuberculosis; in Rom WN, Gray S (eds): Tuberculosis. New York, Little, Brown, 1995, pp 577-583.

18 Nissapatorn V, Kuppusamy I, Wan-Yusoff WS, Anuar AK: Clinical analysis of foreignborn patients with tuberculosis found In Malaysia. Southeast Asian J Trop Med Public Health 2005;36:713-721.
19 Koffi N, Ngom AK, Aka-Danguy E, Seka A, Akoto A, Fadiga D: Smear positive pulmonary tuberculosis in a prison setting: experience in the penal camp of Bouake, Ivory Coast. Int J Tuberc Lung Dis 1997;1:250-253.

20 Gajalakshmi V, Peto R, Kanaka TS, Jha P: Smoking and mortality from tuberculosis and other diseases in India: retrospective study of 43,000 adult male deaths and 35,000 controls. Lancet 2003;362:507-515.

21 Nagayama N: Tuberculosis in Japan at present and in near future. Kekkaku 2001;76: 517-519.

22 Elamin EI, Muttalif AR, Izham MI, Syed AS: A survey on tuberculosis cases in Penang Hospital: preliminary findings. Malays J Pharm Sci 2004;2:1-8.

23 Polesky A, Grove W, Bhatia G: Peripheral tuberculous lymphadenitis: epidemiology, diagnosis, treatment, and outcome. Medicine 2005;84:350-362.

24 Geldmacher H, Taube C, Kroeger C, et al: Assessment of lymph node tuberculosis in northern Germany: a clinical review. Chest 2002;121:1177-1182.

25 Dandapat MC, Mishra BM, Dash SP, Kar PK: Peripheral lymph node tuberculosis: a review of 80 cases. Br J Surg 1990;77:911-912.

26 Weiler Z, Nelly P, Baruchin AM, Oren S: Diagnosis and treatment of cervical tuberculous lymphadenitis. J Oral Maxillofac Surg 2000;58:477-481.

27 Rieder HL: How to combat tuberculosis in the year 2000? Respiration 1998;65:423-431. 